\title{
International Day of Mathematics
}

\section{Christiane Rousseau}

The International Mathematical Union (IMU) is leading the project of having UNESCO proclaim March 14 as the International Day of Mathematics (IDM). The project was adopted by the Executive Board of UNESCO at its 205th session in October 2018. The proclamation of the IDM is on the agenda of the 40th session of the General Conference of UNESCO in November 2019. If adopted by the General Conference, the first official celebration will take place on March 14, 2020. The choice of the date of the IDM was done after consulting the IMU members. March 14, also called Pi Day, is already celebrated in many countries around the world and was proposed by many members. Moreover, the date was convenient for all regions of the world.

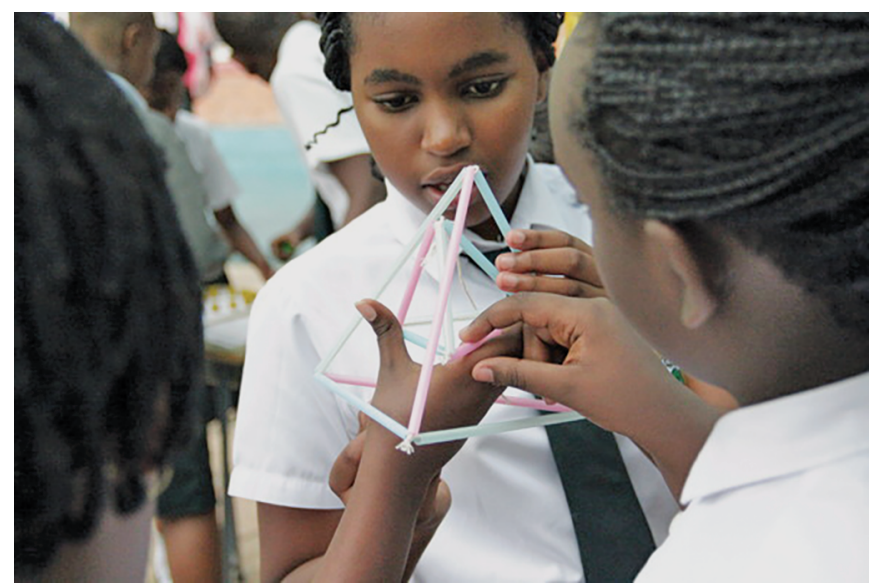

Figure 1. A girl from Kigali at an exhibition of IMAGINARY in 2017.

Christiane Rousseau is a professor of mathematics at Université de Montréal, Montréal, Canada. Her email address is rousseac@dms.umontreal.ca. For permission to reprint this article, please contact: reprint-permission @ams.org.

DOI: https://dx.doi.org/10.1090/noti1928

\section{The Functioning of the IDM}

While mathematical research is mostly published in English, outreach activities and school education take place in local languages. This is a challenge for the IDM. Hence the centralized website of the IDM at http://www. idm314. org will be in several languages. It will be administered by IMAGINARY. ${ }^{1}$ All organizers of celebrations around the world will be invited to post their activities on the IDM website and to include a link to their website for more details. The logo representing the decimals of $\pi$ (see Figure 2) will be produced in several languages, and organizers will be invited to use it.

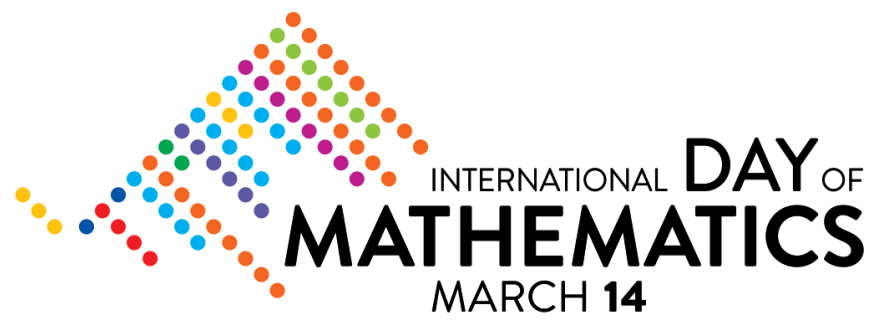

Figure 2. The IDM logo.

The IDM is administered by an IDM Governing Board (IDMGB) that I am chairing. Our Governing Board has the task of choosing the theme of the year. The (nonmandatory) theme is announced in advance, and related open source material will be made available on the IDM website. This will include curriculum enrichment activities and also material for activities to do with the public.

The IDMGB is responsible for making the IDM known in all regions of the world. It will also prepare the official launch at the UNESCO headquarters in Paris. In practice, since March 14, 2020, is a Saturday, this launch will take place on Friday, March 13, 2020.

\footnotetext{
${ }^{1}$ https://imaginary.org
} 


\section{Mathematics Is Everywhere}

"Mathematics Is Everywhere" is the chosen theme for 2020. This very broad theme reaches all of the public, regardless of age, with a wide spectrum of messages. It will be presented with some explanations that could be used as is or could stimulate the organizers to build their own examples.

Mathematics is everywhere in science and technology. A few examples:

- The success of Google comes from its brilliant mathematical algorithm.

- Cryptography for secure communication relies on number theory.

- Medical imaging devices like computed tomography scan (CT-scan) or magnetic resonance imaging (MRI) measure numerical data, and a mathematical algorithm builds an image out of them.

- Artificial intelligence and machine learning are now transforming the world: for instance, computer vision, automatic translation, autonomous vehicles, etc.

- The decoding of the human genome is a triumph of mathematics, statistics, and computer science.

- Mathematics was used to create the first photo of a black hole.

Mathematics is everywhere in the organization of civilization. A few examples:

- Mathematics is used to optimize transport and communication networks.

- Mathematics helps us understand and control the spread of epidemics.

- Statistics and optimization are used in efficient planning and managing of health, economic, and social systems.

Mathematics is essential to meet the UN Sustainable Development Goals. ${ }^{2}$ A few examples:

- Mathematics is a tool for development. Quoting Nelson Mandela (June 1990), "Education is the most powerful weapon which you can use to change the world." And mathematics is an essential part of education, which is necessary for better jobs.

- Mathematics is used to model global changes and their consequences for biodiversity.

- Optimization techniques and data analysis are needed in the move to a sustainable use of the world's resources.

- Mathematics education empowers girls and women for a better future.

- Numeracy and scientific literacy help every citizen to better understand the challenges facing the world around them.
Mathematics is everywhere in our daily life.

- Mathematics inspires artists and musicians: symmetries, tilings, fractals, elegant curves and surfaces; patterns, scales, and sounds in music.

- Mathematics is helpful in games of strategy, from backgammon or chess to solving a Rubik's cube.

- Mathematics is useful in budgeting.

Tell me about some activity or area and I will tell you where mathematics is.

- Mathematics is behind the functioning of GPS.

- Mathematics is behind the software of our smartphones.

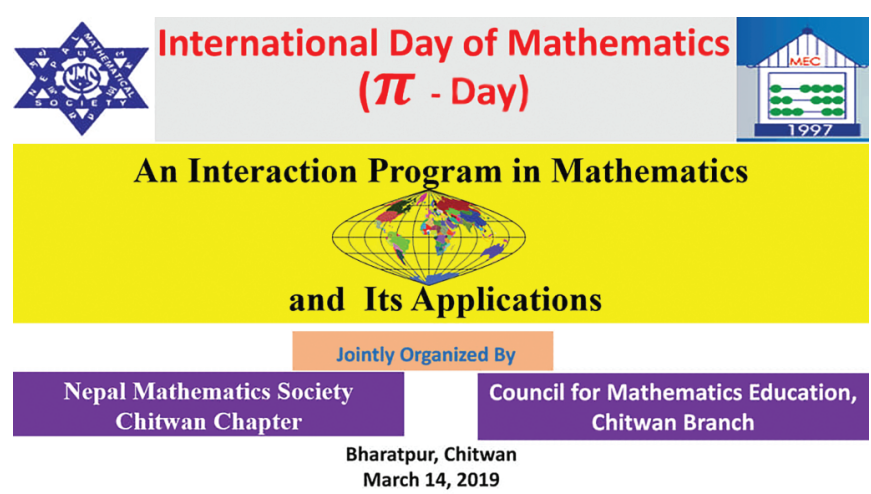

Figure 3. Nepal Mathematics Society started celebrating in 2019.

\section{An Invitation}

Everyone is invited to spread the word about the IDM to her or his network of contacts. Start thinking about the theme and how you can celebrate it in your classroom or with the public. The enthusiasm is great around the world. Some countries could not wait till 2020 to start celebrating (see Figure 3).

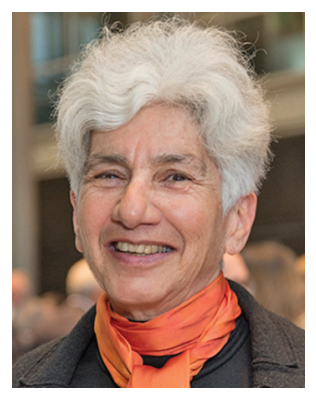

Christiane Rousseau

\section{Credits}

Figure 1 is courtesy of Bianca Violet.

Figure 2 is courtesy of IMAGINARY.

Figure 3 is courtesy of Nepal Mathematics Society.

Author photo is courtesy of Amélie Philibert, University of Montréal.

\footnotetext{
2 https://sustainabledevelopment.un.org/?menu=1300
} 